\title{
Axial Changes of Catalyst Structure and Temperature in a Fixed-Bed Microreactor During Noble Metal Catalysed Partial Oxidation of Methane
}

\section{Journal Article}

Author(s):

Hannemann, Stefan; Grunwaldt, Jan-Dierk; Kimmerle, Bertram; Baiker, Alfons; Boye, Pit; Schroer, Christian

Publication date:

2009-09

Permanent link:

https://doi.org/10.3929/ethz-b-000018818

Rights / license:

In Copyright - Non-Commercial Use Permitted

Originally published in:

Topics in Catalysis 52(10), https://doi.org/10.1007/s11244-009-9315-0 


\title{
Axial Changes of Catalyst Structure and Temperature in a Fixed-Bed Microreactor During Noble Metal Catalysed Partial Oxidation of Methane
}

\author{
Stefan Hannemann · Jan-Dierk Grunwaldt • \\ Bertram Kimmerle · Alfons Baiker • \\ Pit Boye $\cdot$ Christian Schroer
}

Published online: 13 June 2009

(C) Springer Science+Business Media, LLC 2009

\begin{abstract}
The catalytic partial oxidation of methane (CPO) over flame-made $2.5 \% \mathrm{Rh}-2.5 \% \mathrm{Pt} / \mathrm{Al}_{2} \mathrm{O}_{3}$ and $2.5 \% \mathrm{Rh} / \mathrm{Al}_{2} \mathrm{O}_{3}$ in $6 \% \mathrm{CH}_{4} / 3 \% \mathrm{O}_{2} / \mathrm{He}$ shows the potential of in situ studies using miniaturized fixed-bed reactors, the importance of spatially resolved studies and its combination with infrared thermography and on-line mass spectrometry. This experimental strategy allowed collecting data on the structure of the noble metal (oxidation state) and the temperature along the catalyst bed. The reaction was investigated in a fixed-bed quartz microreactor (1-1.5 mm diameter) following the catalytic performance by on-line gas mass spectrometry (MS). Above the ignition temperature of the catalytic partial oxidation of methane $\left(310-330{ }^{\circ} \mathrm{C}\right)$, a zone with oxidized noble metals was observed in the inlet region of the catalyst bed, accompanied by a characteristic hot spot (over-temperature up to $150{ }^{\circ} \mathrm{C}$ ), while reduced noble metal species became dominant towards the outlet of the bed. The position of both the gradient in oxidation state and the hot spot were strongly
\end{abstract}

Electronic supplementary material The online version of this article (doi:10.1007/s11244-009-9315-0) contains supplementary material, which is available to authorized users.

S. Hannemann · J.-D. Grunwaldt $(\bowtie) \cdot$ B. Kimmerle .

A. Baiker

Department of Chemistry and Applied Biosciences, Institute for Chemical and Bioengineering, ETH Zurich, Hönggerberg-HCI, 8093 Zurich, Switzerland

e-mail: grunwaldt@chem.ethz.ch; jdg@kt.dtu.dk

J.-D. Grunwaldt

Department of Chemical and Biochemical Engineering,

Technical University of Denmark, 2800 Kgs. Lyngby, Denmark

P. Boye $\cdot$ C. Schroer

Institute for Structural Physics, Technical University of Dresden,

01062 Dresden, Germany dependent on the furnace temperature and the gas flow (residence time). Heating as well as a higher flow rate caused a migration of the transition zone of the oxidation state/maximum in temperature towards the inlet. At the same time the hydrogen concentration in the reactor effluent increased. In contrast, at low temperatures a movement of the transition zone towards the outlet was observed at increasing flux, except if the self-heating by the exothermic methane oxidation was too strong. The results indicate that in the oxidized zone mainly combustion of methane occurs, whereas in the reduced part direct partial oxidation and reforming reactions prevail. The results demonstrate how spatially resolved spectroscopy can help in understanding catalytic reactions involving different reaction zones and gradients even in micro scale fixed-bed reactors.

Keywords Catalytic partial oxidation of methane . Supported noble metals - Spatially resolved spectroscopy . In situ X-ray absorption spectroscopy · microXAS . Infrared thermography

\section{Introduction}

Miniaturized reaction systems play an increasing role in both in situ spectroscopic studies [1-4] and technical scale catalysis (microreactor arrays; cf. [5, 6]). Due to their reduced scale (reactor dimensions from a few microns to several hundred micrometers) a more precise reaction control can be achieved due to improved heat and mass transfer. This is particularly interesting for highly exothermic reactions such as total and partial oxidation of hydrocarbons or alcohols. The small dimensions are also beneficial for spectroscopic purposes, since the probing 
beam can penetrate small catalyst beds through thin walls more easily and the catalyst can be used in undiluted form. In addition, such devices are optimal for spatially resolved studies.

In situ Raman, XRD, XRF, UV-vis, infrared and X-ray absorption spectroscopic studies have been reported with a $10 \mu \mathrm{m}$ spatial resolution or less [1, 7-9] using small probing beams (scanning spectroscopy/microscopy). Alternatively, full-field imaging with an infrared focal plane array detector or an X-ray camera [8, 10-13] has been used. For example, an X-ray camera has been applied for determining the structure of a catalyst in a spatially resolved manner [8, 11], either for measuring several samples at the same time (parallel structural screening of catalysts) or during a catalytic reaction where concentration/temperature gradients occur.

In this study we extended this approach using both spatially resolved X-ray absorption spectroscopy for analyzing the structure of the catalyst and infrared thermography to determine the temperature gradients. The catalytic partial oxidation of methane over alumina supported Ptand Rh-based catalysts served as case study, which appears relevant because a detailed understanding of the mechanism is still not reached. Mainly two mechanistic routes for the CPO reaction have been proposed:

1. Direct partial oxidation of methane (DPO, reaction II in Table 1, see refs. [14-17]).

2. Catalytic combustion and reforming (CCR, reaction I followed by reaction III and IV, see refs. [18-21]).

Also a combination of both routes may occur. Considering that the catalytic combustion of methane performs better over oxidized noble metals than on reduced species and that it is much more exothermic than the direct partial oxidation of methane, stronger temperature and structural gradients are expected for the CRR mechanism than for the DPO mechanism. These product and temperature variations were also predicted by numerical simulations $[22,23]$.

Spectroscopic data on the CPO of methane were so far mostly collected in an "integral" way, e.g. overall infrared spectroscopy [24], X-ray absorption spectroscopy [21, 25, 26], pulse experiments [16] and temperature jump measurements [27]. Only recently, spatially resolved techniques have been applied. Infrared thermography has uncovered strong temperature gradients in the reactor [19, 28], Horn et al. [29] used spatially resolved mass spectrometry to identify the products inside a catalytic reactor and changes in structure over a catalytic reactor have been reported by Grunwaldt and Baiker [30]. More recently, we have further advanced the techniques to gain insight into gradients on a micrometer scale and focussed on an experimental setup for spatially resolved X-ray absorption spectroscopy [8]. In order to pursue this strategy in more detail we have extended our studies and report herein:

(i) Mapping of the oxidation state in the catalyst bed using a $0.5 \times 0.5 \mathrm{~mm}$ as well as a $5 \times 5 \mu \mathrm{m}$ large $\mathrm{X}$ ray beam and the application of an X-ray camera for 2D-images of the oxidation state distribution both at the $\mathrm{Pt}_{3^{-}}$and $\mathrm{Rh} \mathrm{K}$-edge.

(ii) Axial temperature changes during the partial oxidation of methane and qualitative dependence on the parameters furnace temperature, space velocity and catalyst composition.

(iii) Investigation of the gradients as function of flow, furnace temperature and catalyst composition.

\section{Experimental}

\subsection{Catalyst Preparation}

$2.5 \% \mathrm{Pt}-2.5 \% \mathrm{Rh} / \mathrm{Al}_{2} \mathrm{O}_{3}$ and $2.5 \% \mathrm{Rh} / \mathrm{Al}_{2} \mathrm{O}_{3}$ catalysts were prepared by flame spray pyrolysis using a solution of $\mathrm{Pt}(\mathrm{II})$ acetylacetonate, $\mathrm{Rh}(\mathrm{III})$ acetylacetonate and $\mathrm{Al}(\mathrm{III})$ acetylacetonate in a fresh mixed solution of methanol and acetic acid. The precursor solutions were sprayed into a methane oxygen flame via a nozzle [31, 32]. The powder was collected from the filter and sieved fractions (typically 100-200 $\mu \mathrm{m}$ ) were prepared for the spectroscopic experiments (more details in the ESI).

\subsection{Experimental Setup}

Similar experimental setups were used to monitor the oxidation state in a spatially resolved way along the catalyst bed with a micro X-ray beam or an X-ray camera and to estimate the temperature distribution in axial direction of
Table 1 Different reactions that may occur during the partial oxidation of methane including their standard reaction enthalpies (data from [43] at $25{ }^{\circ} \mathrm{C}$ )

\begin{tabular}{lllll}
\hline Number & Reactants & Products & Reaction & $\Delta_{\mathrm{r}} \mathrm{H}^{\circ}\left(\mathrm{kJ} \mathrm{mol}^{-1}\right)$ \\
\hline I & $\mathrm{CH}_{4}+2 \mathrm{O}_{2}$ & $\mathrm{CO}_{2}+2 \mathrm{H}_{2} \mathrm{O}$ & Total oxidation & -803 \\
II & $\mathrm{CH}_{4}+1 / 2 \mathrm{O}_{2}$ & $\mathrm{CO}+2 \mathrm{H}_{2}$ & Direct partial oxidation & -36 \\
III & $\mathrm{CH}_{4}+\mathrm{H}_{2} \mathrm{O}$ & $\mathrm{CO}+3 \mathrm{H}_{2}$ & Steam reforming & +206 \\
IV & $\mathrm{CH}_{4}+\mathrm{CO}_{2}$ & $2 \mathrm{CO}+2 \mathrm{H}_{2}$ & $\mathrm{CO}_{2}$ reforming & +247 \\
\hline
\end{tabular}


Fig. 1 Schematic view of the in situ cell including the gas blower used for heating from the bottom. On the right hand side an example of a thermographic image at a furnace temperature of $400{ }^{\circ} \mathrm{C}$ (flow rate, $13 \mathrm{~mL} \mathrm{~min}^{-1}$ ) is given. For the temperature scale see Fig. 6

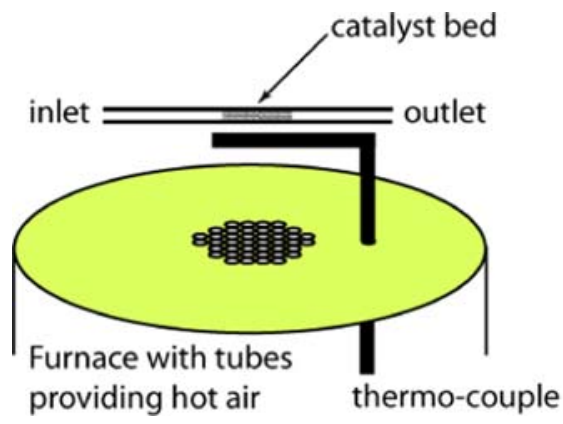

the catalyst bed during the partial oxidation of methane. In all cases, the reaction was conducted over the catalysts loaded in a quartz glass capillary microreactor (Markröhrchen, Hilgenberg $\mathrm{GmbH}, 1.0-1.5 \mathrm{~mm}$ in diameter, 25-35 mm long, $10 \mathrm{~mm}$ catalyst bed, $20 \mu \mathrm{m}$ wall thickness) as described in ref. [33]. The in situ spectroscopic cell is similar to the one that has been proposed for operando XRD measurements [34] and was applied for various spectroscopic studies [35-37]. A schematic figure is shown in Fig. 1. The capillary was heated from below with a mass flow controlled air jet (Brooks, 0-2000 $\mathrm{mL} \mathrm{min}^{-1}$ ). The furnace contained a heating element (ring cartridge, SUVAG, Zurich, $300 \mathrm{~W}, 230 \mathrm{~V}$ ) with a thermocouple (K-type). As shown in Fig. 1, the sample temperature was measured just below the microreactor.

\subsubsection{XAS Studies for the Mapping of Oxidation States}

For spectroscopic studies with the micro X-ray beam and the X-ray camera, the reaction cell was mounted on translational stages to align the microreactor in the beam. Conventional XAS measurements at the $\mathrm{Pt}_{3^{-}}$and the $\mathrm{Rh}$ K-edge and the corresponding measurements with the X-ray camera were performed at HASYLAB at DESY (Hamburg, DORIS III ring operating at $4.4 \mathrm{GeV}$ and a ring current of $140 \mathrm{~mA}$, bending magnet beamline X1) using either a $\mathrm{Si}(111)$ or a $\mathrm{Si}(311)$ double crystal monochromator detuned to about $60 \%$ of the maximum intensity. For the conventional XAS experiments, ionization chambers were used to determine the X-ray intensity. For pre-scanning along the catalyst bed in the quartz capillary a $0.5 \mathrm{~mm} \times$ $0.5 \mathrm{~mm}$ large beam was used. When recording spatially resolved spectra at the $\mathrm{Rh} \mathrm{K}$ - and $\mathrm{Pt} \mathrm{L}_{3}$-edge, a high resolution $\mathrm{X}$-ray camera was used behind the microreactor. In the camera, the X-rays are converted into visible light and amplified by a scintillator. The visible light is then guided through a magnifying optics onto a CCD chip (charged coupled device). This allowed us to record the $\mathrm{X}$ ray intensity with and without the microreactor as function of energy and location in the microreactor. Considering the effective pixel size of $3.5 \mu \mathrm{m}$, a resolution of $5 \mu \mathrm{m}$ could be achieved. The reproducibility of the movement actuated by the motors was better than $1 \mu \mathrm{m}$. So, a significant influence on the errors in data quality can be excluded. Here the intensities were averaged over several pixels which resulted in a resolution of about $20 \mu \mathrm{m}$ but also lower acquisition times. More details can be found in the ESI and ref. [8]. The resulting XAS spectra both from conventional XAS and the XAS spectra from the X-ray camera were analysed in a standard analysis procedure (subtraction of the background and normalization of edge jump). The amount of oxidized and reduced $\mathrm{Rh}$ - and $\mathrm{Pt}-$ species was determined using a linear combination of the XANES spectra. Main errors that are introduced are the signal-to-noise ratio (depends on the variations in the intensity of the beam, the exposure time, the binning of the points, the stability of the catalyst bed, cf. [8]) and the number of species present (here an oxidized and reduced species were assumed). Therefore, in addition, XAS measurements with a micro X-ray beam were performed at the Swiss Light Source (SLS) in Villigen, Switzerland. For this purpose the beam was focussed with a KB-mirror to $5 \mu \mathrm{m} \times 5 \mu \mathrm{m}$ and $\mathrm{Pt} \mathrm{L}_{3}$-edge spectra taken along the axial bed of the reactor.

\subsubsection{Axial Profile by the Infrared Camera}

The temperature distribution was recorded by an infrared camera (FLIR), more specifically a ThermaCAM S65 (Pergam Suisse AG) with data processing using ThermaCAM Researcher Pro 2.8 SR-2. The camera measures and images the infrared radiation emitted by the reactor including other parts of the spectroscopic arrangement (Fig. 1). A wavelength from 7.5 to $13 \mu \mathrm{m}$ of the infrared regime was chosen to estimate the temperature between 200 and $800{ }^{\circ} \mathrm{C}$. The emissivity $(\varepsilon=0.85)$ was corrected automatically by a "Lowtran" algorithm typically used for such thermographic images. The correction is based on ambient and reflected temperature, object distance and humidity. The alumina was the major component of the catalyst and the main emission source, which is reflected in its higher emissivity (noble metals only $0.1-0.3$ [38]). Note that the temperature accuracy is significantly affected by sample inhomogeneities, different emissivities and the 
reaction gas. The relative temperature accuracy is ca. $\pm 2{ }^{\circ} \mathrm{C}$, as reported for similar studies before [10]. A closeup lens was inserted to obtain a local resolution of about $0.1 \mathrm{~mm}$. The distance between lens and sample was $15-25 \mathrm{~cm}$ and the typical recording time was one frame per second.

\subsection{Experimental Procedure}

Pre-mixed $6 \% \mathrm{CH}_{4} / 3 \% \mathrm{O}_{2} / \mathrm{He}$ (PanGas, Switzerland) was fed into the fixed-bed reactor. The flow was adjusted by mass flow controllers (Brooks, $0-50 \mathrm{~mL} \mathrm{~min}^{-1}$ ) and checked beforehand at the outlet of the reactor by a gas flow meter (7-Gas Flow meter, Raczek, Garbsen, Germany). This resulted in residence times between $9 \mathrm{~ms}$ ( $25 \mathrm{~mL} / \mathrm{min}$ in a $1.0 \mathrm{~mm}$ capillary) to $110 \mathrm{~ms}(5 \mathrm{~mL} / \mathrm{min}$ in a $1.5 \mathrm{~mm}$ capillary) assuming a bed porosity of 0.5 . The microreactor was connected to a mass spectrometer (Balzers Thermostar) for online gas analysis. Mass spectrometer (MS) signals were recorded for all relevant fragments $\mathrm{m} / \mathrm{z}(2,4,15,16,28,32$ and 44).

\section{Results}

The partial oxidation of methane over $2.5 \% \mathrm{Rh}-2.5 \% \mathrm{Pt} /$ $\mathrm{Al}_{2} \mathrm{O}_{3}$ and $2.5 \% \mathrm{Rh} / \mathrm{Al}_{2} \mathrm{O}_{3}$ was first studied by "integral" $\mathrm{X}$-ray absorption spectroscopy with a $0.5 \mathrm{~mm} \times 0.5 \mathrm{~mm}$ large X-ray beam, then scanning X-ray absorption spectroscopy at the $\mathrm{Pt}_{3}$-edge using a $5 \times 5 \mu \mathrm{m}$ beam, and finally by using an X-ray camera (full field scanning X-ray absorption microscopy). The results were complemented by measuring the temperature distribution along the catalyst bed with infrared thermography and by determining the catalytic performance by mass spectrometry. Note that the appearance/disappearance of hydrogen was most sensitive for monitoring the ignition/extinction of the partial oxidation of methane and is therefore reported in Table 2 . The conversion towards hydrogen and carbon monoxide started above a characteristic temperature of $300-325^{\circ} \mathrm{C}$ (see e.g. Fig. S3 in the ESI, cf. refs. [25, 32]), where the oxygen was consumed completely and reduced noble metal was detected. The selectivity towards hydrogen and carbon monoxide increased further at higher temperature. The total oxidation of methane to carbon dioxide and water already occurred below the ignition temperature of ca. $320{ }^{\circ} \mathrm{C}$. After the ignition of the partial oxidation of methane to $\mathrm{H}_{2}$ and $\mathrm{CO}$, the reaction could be run at lower temperature than the ignition temperature (hysteresis effect).

3.1 Allocation of the Oxidation State of the Noble Metals Along the Catalyst Bed Using a Macro and a Micro X-ray Beam

Prior to the experiments with full field X-ray absorption microscopy, the ca. $10 \mathrm{~mm}$ long catalyst bed within the quartz capillary was scanned with a $0.5 \mathrm{~mm} \times 0.5 \mathrm{~mm}$ large beam. Whereas below the ignition temperature both $\mathrm{Rh}$ and $\mathrm{Pt}$ were in mostly oxidized state, there was a clear gradient between oxidized species in the beginning of the catalyst bed and reduced species in its end after ignition of the $\mathrm{CPO}$ reaction (towards $\mathrm{CO}$ and $\mathrm{H}_{2}$ ). Selected data of the investigated catalysts are presented in the ESI (Scans A
Table 2 Temperature and flow conditions combined with online mass spectrometric analysis of hydrogen $(\mathrm{m} / \mathrm{z}=2)$ at the outlet of the reactor. The temperature was measured at the outer wall of the capillary. The diameter of reactor was $1.5 \mathrm{~mm}$ in Scans $\mathrm{K}-\mathrm{M}$, whereas in Scans A-I and O-R the diameter was $1.0 \mathrm{~mm}$

\begin{tabular}{|c|c|c|c|c|c|}
\hline Scan & Catalyst & $\begin{array}{l}\text { Temperature } \\
\left({ }^{\circ} \mathrm{C}\right)\end{array}$ & $\begin{array}{l}\text { Total flow } \\
\left(\mathrm{mL} \min ^{-1}\right)\end{array}$ & $\begin{array}{l}\mathrm{m} / \mathrm{z}=2 \\
\text { (in a.u.) }\end{array}$ & Figures \\
\hline A & $2.5 \% \mathrm{Pt}-2.5 \% \mathrm{Rh}$ & 307 & 10 & 0.19 & $\mathrm{~S} 2,9$ \\
\hline B & $2.5 \% \mathrm{Pt}-2.5 \% \mathrm{Rh}$ & 316 & 10 & 0.25 & $\mathrm{~S} 2,9$ \\
\hline $\mathrm{C}$ & $2.5 \% \mathrm{Pt}-2.5 \% \mathrm{Rh}$ & 198 & 16 & 9.5 & 3 \\
\hline $\mathrm{D}$ & $2.5 \% \mathrm{Pt}-2.5 \% \mathrm{Rh}$ & 215 & 23 & 9 & 3 \\
\hline $\mathrm{E}$ & $2.5 \% \mathrm{Pt}-2.5 \% \mathrm{Rh}$ & 313 & 12 & 7.8 & 3 \\
\hline $\mathrm{F}$ & $2.5 \% \mathrm{Pt}-2.5 \% \mathrm{Rh}$ & 322 & 10 & 11 & 3 \\
\hline G & $2.5 \% \mathrm{Pt}-2.5 \% \mathrm{Rh}$ & 212 & 23 & 10 & 4 \\
\hline $\mathrm{H}$ & $2.5 \% \mathrm{Pt}-2.5 \% \mathrm{Rh}$ & 313 & 10 & 8.3 & 4 \\
\hline I & $2.5 \% \mathrm{Pt}-2.5 \% \mathrm{Rh}$ & 322 & 10 & 11 & 4 \\
\hline $\mathrm{K}$ & $2.5 \% \mathrm{Pt}-2.5 \% \mathrm{Rh}$ & 335 & 10 & 2.1 & 8 \\
\hline $\mathrm{L}$ & $2.5 \% \mathrm{Pt}-2.5 \% \mathrm{Rh}$ & 307 & 5 & 2.5 & 8 \\
\hline M & $2.5 \% \mathrm{Pt}-2.5 \% \mathrm{Rh}$ & 316 & 5 & 2.6 & 8 \\
\hline $\mathrm{O}$ & $2.5 \% \mathrm{Rh}$ & 352 & 12.5 & 1.2 & 9 \\
\hline $\mathrm{P}$ & $2.5 \% \mathrm{Rh}$ & 344 & 25 & ca. 1 & 9 \\
\hline Q & $2.5 \% \mathrm{Rh}$ & 338 & 12.5 & 1.5 & 9 \\
\hline $\mathrm{R}$ & $2.5 \% \mathrm{Rh}$ & 338 & 25 & 1.2 & 9 \\
\hline
\end{tabular}




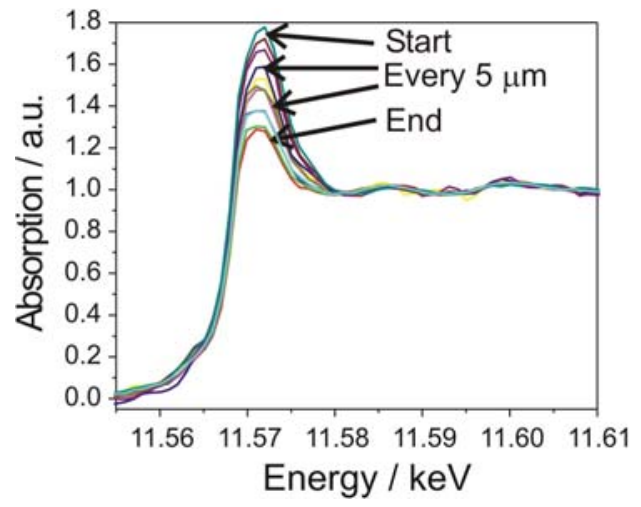

Fig. 2 In situ XANES data during partial oxidation of methane at the $\mathrm{Pt}_{3}$-edge (left) by scanning over the catalyst bed of a $5 \% \mathrm{Pt}-5 \% \mathrm{Rh} /$ $\mathrm{Al}_{2} \mathrm{O}_{3}(0.1-0.2 \mathrm{~mm}$ fraction) using a focussed $5 \mu \mathrm{m} \mathrm{X}$-ray beam and the corresponding data (right) obtained from linear combination of

and B in Fig. S1, catalytic data in Table 2). The transition zone occurred for $\mathrm{Pt}$ and $\mathrm{Rh}$ at the same position and within half a millimetre along the capillary. This corresponds to the resolution achievable with this "macro-beam". The transition zone moved from the inlet more towards the middle of the catalytic bed if the furnace temperature was decreased and concomitantly a lower MS-signal of hydrogen was found (not shown, but compare e.g. ref. [8]). During further heating above $360{ }^{\circ} \mathrm{C}$ (flow rate $10 \mathrm{~mL} \min ^{-1}$ ), the oxidized zone diminished and was finally not detectable anymore by the $0.5 \mathrm{~mm}$ large beam. Increasing the gas flow rate from $10 \mathrm{~mL} \mathrm{~min}^{-1}$ to ca. $20 \mathrm{~mL} \mathrm{~min}^{-1}$ also resulted in an apparently entirely reduced catalyst bed (in a temperature interval of 320$350{ }^{\circ} \mathrm{C}$ ). Below the extinction temperature both $\mathrm{Pt}$ and $\mathrm{Rh}$ were re-oxidized, although not completely since the core of the particles remained in reduced state.

After localizing the transition for a better resolution of the transition region from oxidized to reduced noble metal species, a microfocussed X-ray beam (ca. $5 \times 5 \mu \mathrm{m}$ ) was used and the changes in the axial direction of the catalyst bed were mapped. The results are shown in Fig. 2. Obviously, the changes occur in a range of $100 \mu \mathrm{m}$. Hence, the spectra should be taken with a spatial resolution of $20 \mu \mathrm{m}$ or less. Instead of recording spectra as shown in this section sequentially at every point, we used an X-ray camera and thus full field X-ray microscopy, which is not only speeding up the whole process but also gives the possibility to get 2D-information on the catalyst bed under reaction conditions.

\subsection{Mapping of the Redox Transition by Full-Field X-ray Absorption Spectroscopy Microscopy}

Figure 3 shows the full field microscopy images for oxidized (red) and reduced (blue) $\mathrm{Rh}$ species during four

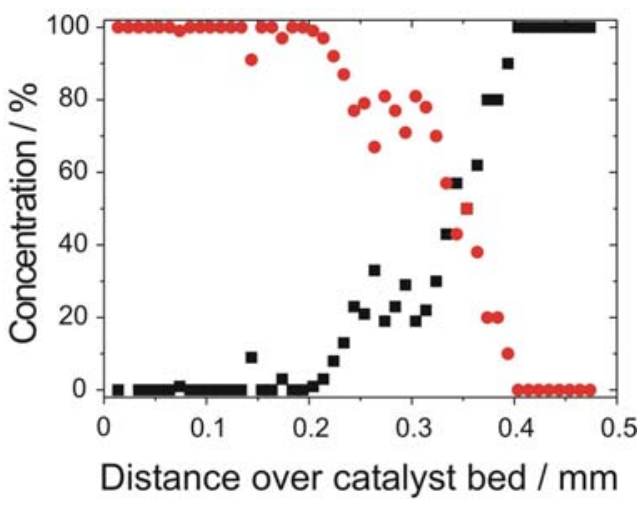

reduced and oxidized reference spectra; conditions: $328^{\circ} \mathrm{C}$, $10 \mathrm{~mL} \mathrm{~min}^{-1}, 1.5 \mathrm{~mm}$ capillary. Bullets represent reduced $\mathrm{Pt}$ and squares the oxidized $\mathrm{Pt}$
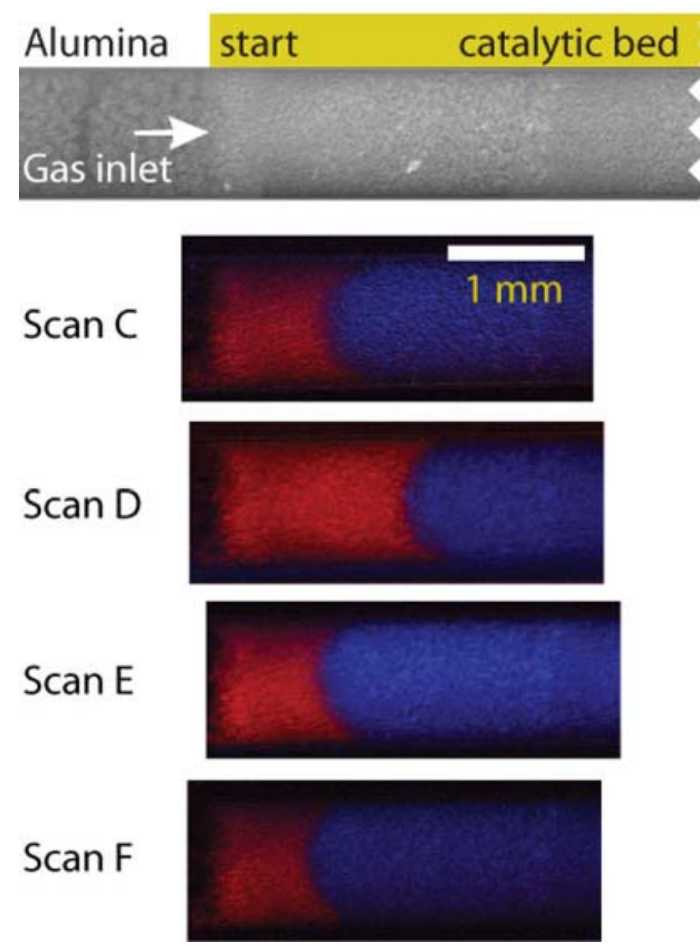

Fig. 3 X-ray absorption image (top, assembled from several pictures) for the first half of the microreactor with images of the transition zone at the Rh-K edge at four different temperature and flow conditions during the catalytic partial oxidation of methane over $2.5 \% \mathrm{Pt}-$ $2.5 \% \mathrm{Rh} / \mathrm{Al}_{2} \mathrm{O}_{3} \quad(0.1-0.2 \mathrm{~mm}$ fraction). Conditions of the scans (temperature of the furnace in brackets) were C: $198(230){ }^{\circ} \mathrm{C}$, $16 \mathrm{~mL} \mathrm{~min}^{-1}$; D: $215(250){ }^{\circ} \mathrm{C}, 23 \mathrm{~mL} \mathrm{~min}^{-1}$; E: $313(360){ }^{\circ} \mathrm{C}$, $12 \mathrm{~mL} \mathrm{~min}^{-1}$; F: $322(370){ }^{\circ} \mathrm{C}, 10 \mathrm{~mL} \mathrm{~min}^{-1}$. Red pixels represent oxidised, blue pixels reduced rhodium species; each image is $3 \mathrm{~mm}$ wide

different reaction conditions in the reactor. The concentration of oxidized and reduced $\mathrm{Rh}$ species was extracted by recording XAS spectra with the X-ray camera followed by extraction of XANES spectra at each point and using a 
linear combination of spectra for oxidized and reduced $\mathrm{Rh}$ species and a featureless background. The corresponding spectra used for the linear combination at the Rh K-edge are depicted in the ESI (Fig. S2). Note that each of the images was a result of recording X-ray absorption images as a function of X-ray energy over $1-1 \frac{1}{2} \mathrm{~h}$. On the top of Fig. 3 an overview of the left part (inlet side) of the capillary is represented by merging $\mathrm{X}$-ray absorption images ( $3 \mathrm{~mm}$ in width) taken along the reactor. The catalyst bed (length was approximately $9 \mathrm{~mm}$ ) exhibited a slightly different X-ray absorbance compared to pure $\mathrm{Al}_{2} \mathrm{O}_{3}$ (loaded as inert material at both ends of the catalyst bed) and is schematically indicated above the X-ray image. The gradient in all images representing the distribution of metallic and oxidized Rh-species exhibited a cone-like shape. Note that in all figures the gas inlet is on the left.

Analogous XAS measurements have been undertaken at the $\mathrm{Pt}_{3}$-edge (Fig. 4, the extracted spectra are given in Fig. S2). Principally, the distinction of oxidized and reduced Pt spectra (see also ESI, Fig. S2) is almost limited to the white-line at $11570 \mathrm{eV}$. Artefacts are therefore more easily reflected in the mappings than at the $\mathrm{Rh} \mathrm{K}$-edge. $\mathrm{Pt}$ $\mathrm{L}_{3}$-edge spectra contain less characteristic EXAFS features than the $\mathrm{Rh} \mathrm{K}$-edge spectra and therefore the resulting images (placed below the overview in Fig. 4) are not as highly resolved as at the Rh K-edge, but still clearly distinguishable. Note also that the "oxidized particles" are not
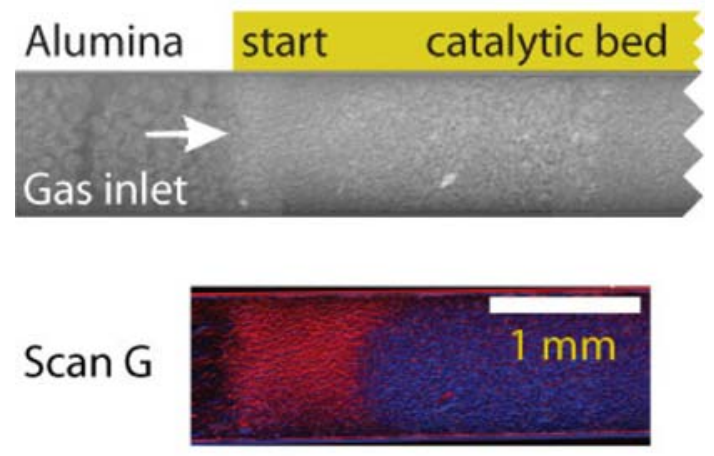

Scan $\mathrm{H}$

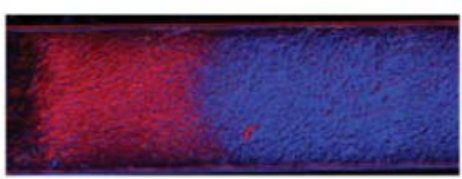

Scan I

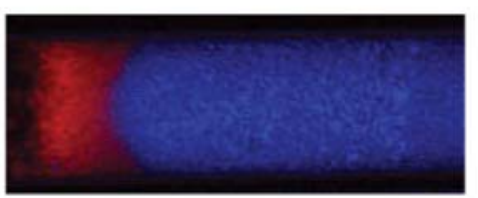

Fig. 4 X-ray absorption image (top) with images of the transition zone at the Pt- $\mathrm{L}_{3}$ edge with the following conditions of the scans were G: $212(246){ }^{\circ} \mathrm{C}, 23 \mathrm{~mL} \mathrm{~min}^{-1}$; $\mathrm{H}: 313(360){ }^{\circ} \mathrm{C}, 10 \mathrm{~mL} \mathrm{~min}{ }^{-1}$; I: $322(370){ }^{\circ} \mathrm{C}, 10 \mathrm{~mL} \mathrm{~min}^{-1}$

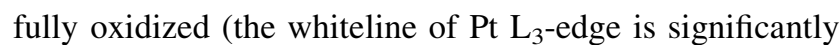
smaller than for $\mathrm{PtO}_{2}$, see [32] for comparison), which is similar to previous observations that report that the particles are composed of an oxidized surface with a metallic core [26].

\subsection{Acquisition of Temperature Profiles by the IR Camera}

As complementary information to the structural data, we studied the temperature distribution upon variation of the gas flow and the furnace temperature (Figs. 5, 6, 7). While the reaction from methane towards $\mathrm{CO}$ and hydrogen was

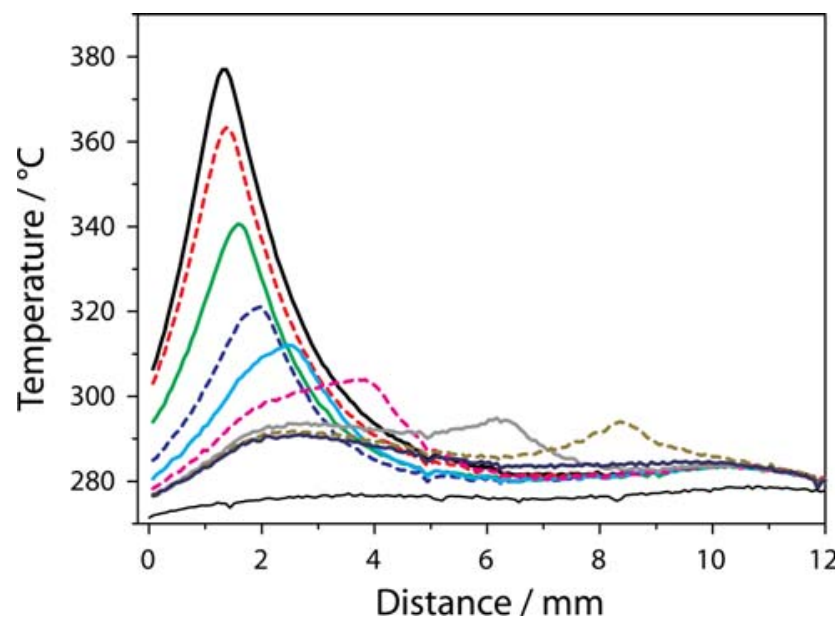

Fig. 5 Temperature profiles of $2.5 \% \mathrm{Pt}-2.5 \% \mathrm{Rh} / \mathrm{Al}_{2} \mathrm{O}_{3}(0.1-0.2 \mu \mathrm{m})$ in the same quartz microreactor as for the XAS studies during CPO of methane at a furnace temperature of $325^{\circ} \mathrm{C}$ and a decreasing flow rate from 27 to $10 \mathrm{~mL} \mathrm{~min}^{-1}$ within $2 \mathrm{~min}$. The thin line (bottom) indicates the profile without reaction and is shifted by $30{ }^{\circ} \mathrm{C}$

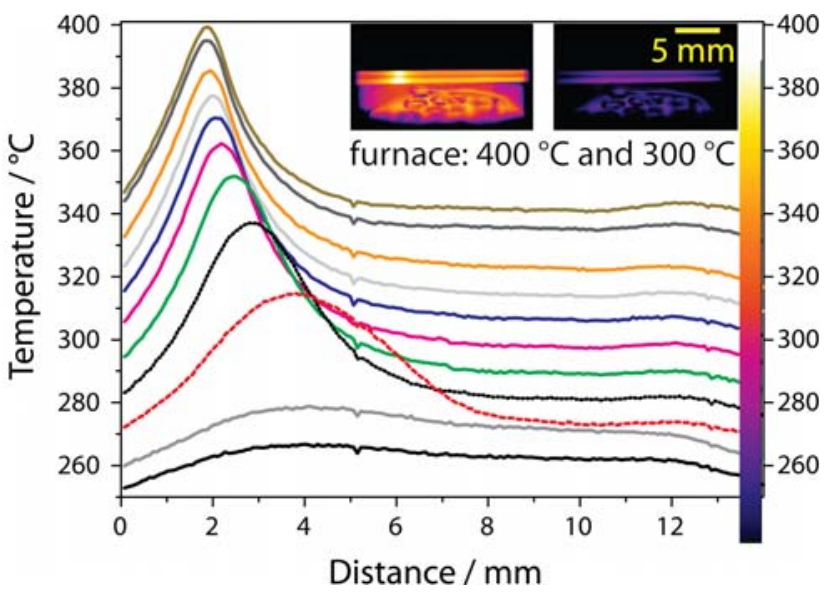

Fig. 6 Temperature profiles of $2.5 \% \mathrm{Rh} / \mathrm{Al}_{2} \mathrm{O}_{3}$ during $\mathrm{CPO}$ of methane at a constant flow of $13 \mathrm{~mL} \mathrm{~min}^{-1}$ for furnace temperatures from 400 to $300{ }^{\circ} \mathrm{C}$ in $10 \mathrm{~K}$ steps. Insets show the temperature distribution at 300 and $400{ }^{\circ} \mathrm{C}$. The temperatures are corresponding to the scale on the upper right 


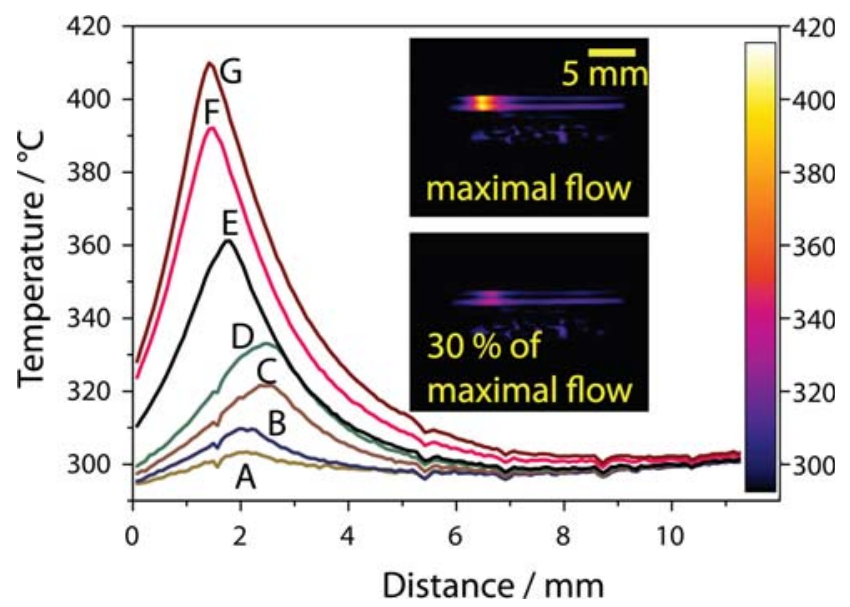

Fig. 7 Axial temperature profiles of $2.5 \% \mathrm{Pt}-2.5 \% \mathrm{Rh} / \mathrm{Al}_{2} \mathrm{O}_{3}(16.5 \mathrm{mg})$ in a $1.5 \mathrm{~mm}$ quartz microreactor during $\mathrm{CPO}$ of methane at a furnace temperature of $350{ }^{\circ} \mathrm{C}$ using increasing flow rates $\left(\mathrm{mL} \mathrm{min}^{-1}\right)$. A: 1.5 , B: 3, C: 7, D: 10, E: 17, F: 26, G: 33. In the insets the temperature distribution is demonstrated for 33 and $10 \mathrm{~mL} \mathrm{~min}^{-1}$

running, a hot spot in the middle or the beginning of the catalyst bed was observed. The position was very sensitive on the conditions. Figures 5 and 6 reflect typical observations: At high space velocities the hot spot shifted more towards the outlet when the flow was decreased. The hot spot also shifted to the end of the catalysts bed if the temperature decreased (Fig. 6) or moved to the beginning if the temperature increased. Figure 7 shows that the influence of the space velocity is more complex than shown by Fig. 5: At low space velocities a shift of the gradient more towards the end is observed, which is the expected trend when self-heating is not too strong since more methane/oxygen has to be along the catalyst bed until reforming can take place. Once again, at higher space velocities an increase of the hot spot and its movement towards the beginning of the catalyst bed due to selfheating was observed (Fig. 7). Note that an even temperature distribution was found if hardly any methane conversion occurred (bottom profile in Fig. 5). Both the effect of flow and furnace temperature on structure and catalyst bed temperature profiles are discussed in Sects. 3.4 and 3.5.

\subsection{Effects of the Variation of the Furnace \\ Temperature on 2D-XAS and IR Profiles}

Upon heating a shift of the transition zone between oxidized and reduced particles as well as of the hot spot towards the inlet and vice versa was observed. The signals for $\mathrm{CO}$ and $\mathrm{H}_{2}$ increased and $\mathrm{O}_{2}$ was fully consumed. For example, a temperature increase from 313 to $322{ }^{\circ} \mathrm{C}$ in Fig. 3 (Scans E and F) led to a movement of the transition zone monitored at the Rh K-edge towards the inlet of the reactor accompanied by an increased formation of $\mathrm{CO}$ and
$\mathrm{H}_{2}$ (Table 2). The same effect was found at the $\mathrm{Pt}_{3}$-edge. Scans $\mathrm{H}$ and I demonstrate a shift of the transition zone towards the inlet when heating up by $10{ }^{\circ} \mathrm{C}$ from $313{ }^{\circ} \mathrm{C}$ at increasing signals for hydrogen and carbon monoxide (Scans H and I). The comparison of the gradients and their shapes both at the Rh K-edge (Fig. 3) and at the $\mathrm{Pt} \mathrm{L}_{3}$-edge (Fig. 4) reveals a similar behaviour for both noble metals. This corresponds to the dynamic behaviour of the data recorded with the IR thermography camera. During cooling a shift towards the end of the reactor (Fig. 6) and vice versa were observed. The change in gradient occurred without retardation but slight changes still occurred over a time of 0.5 to $1 \mathrm{~h}$. When the temperature set-point was lowered even below the ignition temperature, the over-temperature depending on the available combustion heat, still kept the reaction running. This effect is found, e.g. in the first two images of Fig. 3. In both cases (Scan C: $198{ }^{\circ} \mathrm{C}$, $16 \mathrm{~mL} \mathrm{~min}^{-1}$; D: $215^{\circ} \mathrm{C}, 23 \mathrm{~mL} \mathrm{~min}^{-1}$ ) the furnace temperature was significantly lower than the ignition temperature. Thus, a sufficient flow of $\mathrm{CH}_{4} / \mathrm{O}_{2}$ was required to maintain the temperature in the bed. At $200{ }^{\circ} \mathrm{C}$ and $8 \mathrm{~mL} \mathrm{~min}{ }^{-1}$, the reaction extinguished and only the total oxidation of methane was observed leading to a complete re-oxidation of the catalyst bed with no transition zone observable.

In Fig. 6, 11 profiles for $2.5 \% \mathrm{Rh} / \mathrm{Al}_{2} \mathrm{O}_{3}$ in the cell at a furnace temperature between 400 and $300{ }^{\circ} \mathrm{C}$ are depicted (10 ${ }^{\circ} \mathrm{C}$-steps). When cooling the furnace, the over-temperature decreased, the hot spot broadened and moved towards the outlet of the microreactor. This behaviour is in analogy to the transition zone when comparing 322 and $313{ }^{\circ} \mathrm{C}$ (Fig. 4, e.g. Scans I vs. H). Apart from variations observed for the hot spot, the profile lines $\left(400\right.$ to $320{ }^{\circ} \mathrm{C}$ furnace temperature) decreased by equidistant temperature steps. The over-temperature measured according to the infrared camera dropped to $40{ }^{\circ} \mathrm{C}$ at a furnace temperature of $320{ }^{\circ} \mathrm{C}$. In the extinction zone between $320{ }^{\circ} \mathrm{C}$ (dotted line) and $310{ }^{\circ} \mathrm{C}$ not only the hot spot moved to the outlet and disappeared, but also the temperature difference between both temperature profiles decreased, in particular at a distance of $8-10 \mathrm{~mm}$ (Fig. 6). The two profiles at the bottom are parallel with a similar temperature difference of the baseline as measured above ignition. The conversion of methane dropped from about $25 \%$ above ignition temperature to $>15 \%$ just below the extinction temperature (corresponds to the two bottom graphs of Fig. 6). Note that at furnace temperatures $>400{ }^{\circ} \mathrm{C}$, the hot spot was almost at the beginning of the catalyst bed and using the X-ray camera with the resolution applied here no fully oxidized particles could be detected anymore. Thus, the catalyst bed is probably almost fully reduced at higher temperatures due to self reduction of the noble metal particles except a very small fraction of the catalyst bed $(<20 \mu \mathrm{m})$. 


\subsection{Effects of the Variation of the Gas Flow} on 2D-XAS and IR-Profiles

In general, an increase of the gas flow caused a migration of the hot spot and transition towards the inlet and vice versa (see for example Fig. 5). However, at low temperatures just above ignition a higher flow led to a movement to the opposite direction. This is the expected effect if selfheating of the catalyst bed is not dominant since more methane can be converted over the length of the catalyst bed. One example for the corresponding movement of the hot spot on $2.5 \% \mathrm{Pt}-2.5 \% \mathrm{Rh} / \mathrm{Al}_{2} \mathrm{O}_{3}$ is depicted in Fig. 7 . The flow was varied between 1.5 and $33 \mathrm{~mL} \mathrm{~min}^{-1}$ at a furnace temperature of $350{ }^{\circ} \mathrm{C}$. In both thermographic images $\left(10 \mathrm{~mL} \min ^{-1} ; 33 \mathrm{~mL} \mathrm{~min}^{-1}\right)$ a hot spot is visible. A migration of the hot spot towards the inlet of the reactor was observed when increasing the flow to $33 \mathrm{~mL} \mathrm{~min}^{-1}$. A time-resolved analysis of the axial temperature profiles of the reactor, however, uncovered that the direction of migration was differing below (A-D) and above $10 \mathrm{~mL} \min ^{-1}$ (D-G). In the first profiles, the hot spot moved towards the outlet while the maximum temperature increased up to $330{ }^{\circ} \mathrm{C}$, i.e. an over-temperature of $30{ }^{\circ} \mathrm{C}$. In addition, the hot spots were asymmetric. Such a behaviour was also found for the shift of the transition zone from oxidized to reduced noble metal particles. The transition zone at Scan $\mathrm{C}\left(198{ }^{\circ} \mathrm{C}, 16 \mathrm{~mL} \mathrm{~min}^{-1}\right.$, Fig. 3) moved by about half a millimetre towards the outlet in Scan D $\left(215^{\circ} \mathrm{C}, 23 \mathrm{~mL} \mathrm{~min}^{-1}\right)$ due to the increased flow. More gas passed through the catalytic bed and thus more methane had to be converted requiring a longer part of the catalytic bed.

In the second part of the series in Fig, 7, at higher flow rates (up to $33 \mathrm{~mL} \mathrm{~min}^{-1}$, Fig. 7 , profiles $\mathrm{D}$ to $\mathrm{G}$ ), the temperature of the hot spot increased further from 360 to $410{ }^{\circ} \mathrm{C}$ (over-temperature of up to $110^{\circ} \mathrm{C}$ ). The hot spot shifted towards the inlet until it reached the entrance of the catalytic bed. In fact, the released heat even caused a higher temperature at the thermocouple just below the reactor. The shifts of the hot spot correspond to the shift of the oxidation state gradient of Pt and Rh measured by XAS (cf. Figs. 3 and 4) and a movement of the transition zone towards the inlet was observed when the flow was increased.

When lowering the flow rate from 27 to $10 \mathrm{~mL} \mathrm{~min}^{-1}$ (Fig. 5, 2.5\% Pt-2.5\% Rh/ $\left.\mathrm{Al}_{2} \mathrm{O}_{3}\right)$ during $2 \mathrm{~min}\left(325^{\circ} \mathrm{C}\right)$ the hot spot moved from the inlet region of the catalyst bed towards the outlet. The corresponding over-temperature dropped drastically from almost 100 to $25^{\circ} \mathrm{C}$. At an overtemperature of $25^{\circ} \mathrm{C}$, a strong and rapid shift of the hot spot occurred. Since the catalyst bed had a limited length the reaction was extinguished and no hydrogen was detectable anymore after the hot spot reached the end of the

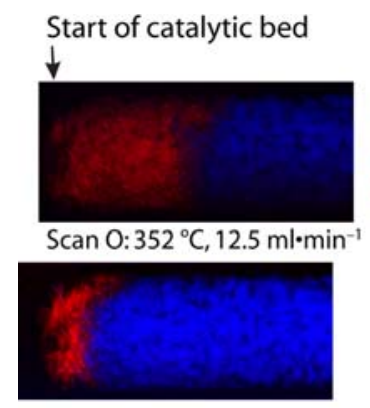

Scan P: $344^{\circ} \mathrm{C}, 25 \mathrm{ml} \cdot \mathrm{min}^{-1}$

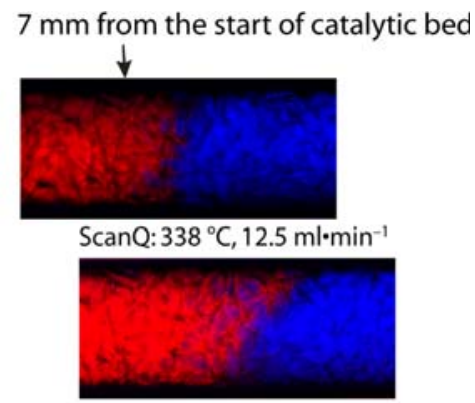

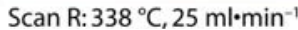

Fig. 8 Mapping of the transition zone of $2.5 \% \mathrm{Rh} / \mathrm{Al}_{2} \mathrm{O}_{3}(14.5 \mathrm{mg}$ ), in a quartz capillary during CPO under the conditions indicated. The location of the catalytic bed is indicated by an arrow for both rows of images. The image width corresponds to $3 \mathrm{~mm}$

catalyst bed and disappeared. Like in Fig. 6 there is still an exothermic reaction towards $\mathrm{CO}_{2}$ and $\mathrm{H}_{2} \mathrm{O}$ leading to a smaller temperature maximum of $10{ }^{\circ} \mathrm{C}$ over-temperature at $2-3 \mathrm{~mm}$. The reverse effect could typically be observed when the flow was increased after ignition (Fig. 8).

\subsection{Variation of Catalyst and Low Space Velocities}

\subsubsection{Results with $2.5 \% \mathrm{Rh} \mathrm{Al}_{2} \mathrm{O}_{3}$}

Like in the case of $2.5 \% \mathrm{Pt}-2.5 \% \mathrm{Rh} / \mathrm{Al}_{2} \mathrm{O}_{3}$ a shift of the transition zone towards the inlet of the reactor occurred with increasing furnace temperature as demonstrated in Fig. 9 (Scan Q vs. Scan O and Scan R vs. Scan P) and the position of the transition zone upon flow increase depended on temperature. The images that were recorded at 12.5 and $25 \mathrm{~mL} \mathrm{~min}^{-1}$ are presented in Fig. 9. At high temperatures the transition zone was shifted towards the inlet (Fig. 9, Scan $\mathrm{O}$ vs. $\mathrm{P}$ ), in contrast to $338{ }^{\circ} \mathrm{C}$ where it was shifted towards the outlet of the reactor (Fig. 9, Scan Q vs. R). Analogous behaviour was observed for the movement of the hot spot with infrared thermography. The shift of the transition zone towards the outlet at $338{ }^{\circ} \mathrm{C}$ is associated with a decrease in the hydrogen signals. From the positioning of the transition zone at $8 \mathrm{~mm}$ (Scan R) it can be concluded that $8 \mathrm{~mm}$ of the catalytic bed (of ca. $10 \mathrm{~mm}$ in total) were necessary to establish conditions required for the reduction of $\mathrm{Rh}$. This latter dependence of the position on the flow is comparable to Scans C and D $\left(198{ }^{\circ} \mathrm{C}\right.$, $16 \mathrm{~mL} \min ^{-1}$ vs. $215^{\circ} \mathrm{C}, 23 \mathrm{~mL} \min ^{-1}$, Fig. 3).

\subsubsection{Results with Low Space Velocities}

In order to increase the residence time a larger capillary diameter of $1.5 \mathrm{~mm}$ was chosen. As a consequence, wide oxidized and reduced zones were found at lower flow rates (5-10 $\mathrm{mL} \mathrm{min}^{-1}$ ). The transition zones (see Fig. 9) were situated on the inlet side. The comparison of Scans $\mathrm{K}$ and $\mathrm{L}$ 


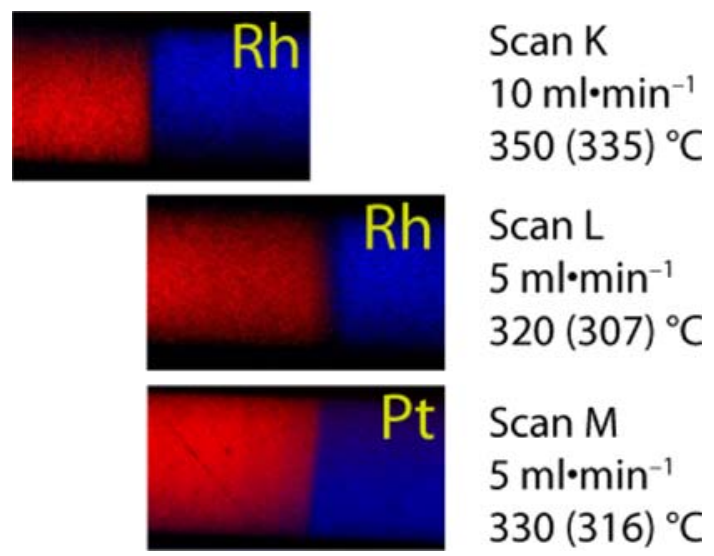

Fig. 9 Images of the transition zone of $2.5 \% \mathrm{Rh}-2.5 \% \mathrm{Pt} / \mathrm{Al}_{2} \mathrm{O}_{3}$ (16.5 mg, $0.05-0.1 \mathrm{~mm}$ sieved fraction) in a $1.5 \mathrm{~mm}$ quartz capillary at the $\mathrm{Rh} \mathrm{K}$ - and $\mathrm{Pt}_{3}$-edges. Each image is $3 \mathrm{~mm}$ wide

(Fig. 9) at the Rh K-edge shows that movement of the transition zone towards the outlet is caused by both decreased temperature $\left(350\right.$ vs. $\left.320^{\circ} \mathrm{C}\right)$ and decreased flow $\left(10\right.$ vs. $\left.5 \mathrm{~mL} \mathrm{~min}^{-1}\right)$. About the same position of the transition zone was observed at $5 \mathrm{~mL} \mathrm{~min}{ }^{-1}$ for Scan $\mathrm{L}$ $\left(307{ }^{\circ} \mathrm{C}\right)$ at the Rh K-edge and for Scan $\mathrm{M}$ at the $\mathrm{Pt}_{3^{-}}$ edge $\left(316^{\circ} \mathrm{C}\right.$, where the hydrogen formation rate was kept constant). Most interestingly, the profile was always straight and perpendicular to the catalytic bed. Apart from the fact that it was easier to stabilize the transition zone of the oxidation state with this experimental arrangement (larger capillary, smaller sieved fraction), the transition zone was localized closer to the middle of the catalyst bed.

\section{Discussion}

\subsection{Advantages and Frontiers of Spatially Resolved Spectroscopy and Infrared Thermography Under In Situ Conditions}

The results from both spatially resolved X-ray absorption spectroscopy and determination of the axial temperature gradient show that in exothermic reactions, as encountered here, it is advantageous not only to measure the structure in a spatially resolved way but also the temperature distribution. Although the present reactor design is of much smaller dimensions than a technical reactor, the gradients are still significant. The advantage is, however, that the spectroscopic techniques applied can unravel information over the whole catalyst bed. Principally, for determining the structure a micro X-ray beam (scanning X-ray microscopy) could be used as it is known from microRaman studies, but the acquisition of data is time-consuming, except the data are taken with a rapidly moving monochromator crystal (QEXAFS, cf. [39]) or using the dispersive EXAFS technique [40]. Here, an X-ray camera was used to parallelize the process and it was shown that this is not only applicable at the Rh K-edge but also at other edges such as the $\mathrm{Pt}_{2}$-edge. The main criterion for distinguishing between the different species is a sufficiently pronounced difference in the XANES spectrum. XANES is here used as a "fingerprint" and proper characterization at selected points then still has to be performed by EXAFS (cf. discussion further below). The complete images in the present studies could be determined within less than $1 \frac{1 / 2}{h}$, which allowed us studies as function of different parameters such as space velocity, temperature, catalyst type and reactor geometry. The influence of the recording time on the data quality has been described in ref. [41]. These studies were compared to the axial changes in the temperature and combined with the overall catalytic performance. This allowed gaining further interesting insight into the course of the partial oxidation of methane. Nevertheless, macro and microXAS studies are still important to provide detailed structural information. It has been shown previously [25] that not metallic Rh but rather Rh-carbonyl species form under reaction conditions, which cannot be concluded from the studies here focussing on the XANES region. Alloy formation of such noble particles has been further addressed in ref. [41] and also the influences of particle size on the XANES spectra has been well described [42]. Such information may be better extracted with microEXAFS at different selected points, which in fluorescence mode together with the QEXAFS technique can also give information on low-concentrated samples.

\subsection{Implications on the Course of the CPO of Methane Over Noble Metal Catalysts}

Under the conditions applied here both on $2.5 \% \mathrm{Rh}-$ $2.5 \% \mathrm{Pt} / \mathrm{Al}_{2} \mathrm{O}_{3}$ and $2.5 \% \mathrm{Rh} / \mathrm{Al}_{2} \mathrm{O}_{3}$ a strong axial temperature gradient was observed, which can be explained with the very exothermic process of the total oxidation of methane. Already before the ignition of the partial oxidation of methane to $\mathrm{CO}$ and hydrogen, total oxidation of methane with an increased temperature towards the end of the catalyst bed is observed. If oxygen is completely consumed, hydrogen and $\mathrm{CO}$ are detected at the end of the catalyst bed. This scenario is only observed if there is a hot spot in the beginning or middle (but not at the end) of the catalyst bed. In the temperature interval that we focussed on this is correlated to a zone with oxidized noble metal clusters in the first part of the catalyst bed and reduced noble metal particles along the downstream part of the catalyst bed. Both the length of the zone with oxidized noble metal clusters in the beginning and the position of the hot spot in the characteristic temperature profile are correlated to each other: For example, an increase of the 
temperature moved the position of the hot spot and the position, where the transition from oxidized to reduced noble metals occurred, more towards the beginning of the catalyst bed. The opposite was observed when the temperature was decreased. Usually, the oxidized zone became also larger and the hot spot was moved more towards the end of the catalyst bed when the methane/oxygen flow was increased because more methane had to be converted until no oxygen was present anymore. An exception was found at sufficiently high temperatures $\left(>350{ }^{\circ} \mathrm{C}\right)$ and high methane/oxygen-flows. In this case a self-heating of the catalyst bed occurred as the results from IR thermography showed. This self-heating is also the reason for the observed hysteresis in the catalytic activity when cooling down the furnace. As the temperature profiles indicate, a characteristic hot spot remained even below the ignition temperature that moved to the end of the catalyst bed correlated with the increase of the length of the oxidized zone of the catalyst. Also in all these cases the presence and concentration of hydrogen was correlated to the position of the hot spot and the length of the reduced zone.

This picture is similar to that of the CRR mechanism [43], where oxidation of methane is proposed in the first part of the reactor and reforming in the downstream part of the catalyst bed. The presence of oxidized noble metal species is probably beneficial for the catalytic combustion in the first part of the reactor, since it has been reportedaccording to a Mars-van Krevelen mechanism-that total oxidation of methane occurs more efficiently over noble metal surfaces covered with oxygen (or being oxidized) than on reduced noble metal surfaces [44, 45]. Since the oxidized zone becomes smaller and smaller, the total oxidation of methane may be taken over by reduced noble metal particles at higher temperatures due to their autoreduction. Total oxidation in the first part probably still prevails since the hot spot moves further and further to the beginning of the catalyst bed and the over-temperature becomes higher. Such a characteristic hot spot is not specific for our catalyst but has been reported also for other noble metal catalysed partial oxidations [46-48]. This also agrees with previous reactor simulations [22, 23].

The processes occurring in the second zone (reduced and after the hot spot) are more complex. After ignition and thus the establishment of the reduced zone, the oxygen signal disappeared. Thus, there is no oxygen present in the last part of the catalyst bed excluding DPO in this area. Behind the hot spot the temperature decreases and rises up slightly just at the end of the catalytic bed. This was also observed by others [19, 28, 43] and similarly for the oxidative steam reforming [49]. This shape can only be explained by an endothermic process supporting that catalytic reforming takes place in this zone. In line with this, $\mathrm{H}_{2}$ and $\mathrm{CO}$ formation increases when the reduced zone broadens. The endothermic reforming reaction occurs preferentially on metallic sites where the activation barrier is lower and benefits from higher temperatures and an extended catalytic bed. At the start of the reduced zone, where the over-temperature of the hot spot is elevated, the reaction rate will be highest. Under dynamic conditions (Figs. 6 and 7) a movement of the hot spot towards the end is observed and at the same time the hydrogen concentration drops. Coincident with the moment where the hot spot reaches the end of the reactor, oxygen appears and hydrogen is not observed anymore. Although no $\mathrm{H}_{2}$ was observed if still some oxygen was present in the feed, also DPO can contribute to the formation of $\mathrm{CO}$ and $\mathrm{H}_{2}$ in the zone of higher over-temperatures. As outlined before, the DPO mechanism has been proposed in several studies before [14-17]. However, it should be noted that these studies were usually performed under different reaction conditions, i.e. higher temperature, and here dynamic spatially resolved studies of the oxidation state may give more information. At higher temperatures the zone of oxidized noble particles seems to be extremely small or due to the autoreduction of the noble metals it will completely disappear. Nevertheless, IR thermographs still indicate a strongly exothermic reaction even at the higher temperatures that let us speculate that to a significant extent total oxidation of methane occurs over metallic noble metal particles, which is also in agreement with recent reactor simulations [22, 23].

\section{Conclusion}

The partial oxidation of methane has been investigated on two noble metal based catalysts in a fixed-bed microreactor by both recording spatially resolved X-ray absorption spectra using an X-ray sensitive camera (full-field X-ray microscopy) and a micro X-ray beam as well as temperature profiling using an infrared camera. This gave important insight into the reaction mechanism, in particular around the ignition temperature of the reaction. Among the two suggested mechanisms (DPO and CCR) the catalytic combustion and reforming mechanism prevails at lower temperatures but at higher temperature DPO may play an important role especially in the hot part of the reactor. Under the conditions applied in this study in the first part of the catalytic bed the noble metal particles are in oxidized state, in contrast to mainly reduced ones in the second part of the reactor. The total oxidation of methane mainly occurs over oxidized noble metal particles leading to a hot spot in the first part of the catalytic reactor. This assignment is also supported by the product gas composition, i.e. more hydrogen is produced if the hot spot moves towards the inlet. The furnace temperature as well as the reactant 
flow strongly influence the location of the transition zone from oxidized to reduced noble metal particles inside the catalyst bed as well as the position of the hot spot. In general, the study demonstrates the importance of spatially resolved spectroscopic studies and the measurement of the temperature profiles even in micro scale fixed-bed reactors as the one used in this study.

Acknowledgements We thank HASYLAB at DESY (Hamburg, Germany) for providing beamtime and support by Dr. Adam Webb, Mathias Herrmann and Bernd Reime throughout the measurements at the beamline X1. Furthermore, we are grateful to SLS (Villigen, Switzerland) for providing beamtime including support by Dr. C. Borca and Dr. D. Grolimund at the microXAS beamline. Pergam Suisse AG (Zurich, Switzerland) is thanked for lending the infrared camera and the help with its handling. Financial support for the spatially resolved XAS measurements is gratefully acknowledged by DESY/HASYLAB and the European Community - Research Infrastructure Action under the FP6: "Structuring the European Research Area" ("Integrating Activity on Synchrotron and Free Electron Laser Science” (IA-SFS) RII3-CT-2004-506008).

\section{References}

1. Cao E, Firth S, McMillan PF, Gavriilidis A (2007) Catal Today 126:119

2. Chan EM, Marcus MA, Fakra S, ElNaggar M, Mathies RA, Paul Alivisatos A (2007) J Phys Chem A 111:12210

3. Beato P, Kraehnert R, Engelschalt S, Frank T, Schlögl R (2008) Chem Eng J 135S:247

4. Clausen BS, Steffensen G, Fabius B, Villadsen J, Feidenhans'1 R, Topsøe H (1991) J Catal 132:524

5. Ehrfeld W, Hessel V, Löwe H (2000) Microreactors: new technology for modern chemistry. Wiley-VCH, New York

6. Gavriilidis A, Angeli P, Cao E, Yeong KK, Wan YSS (2002) Chem Eng Res Des 80A:3

7. Schroer CG, Kuhlmann M, Gunzler TF, Lengeler B, Richwin M, Griesebock B, Lutzenkirchen-Hecht D, Frahm R, Ziegler E, Mashayekhi A, Haeffner DR, Grunwaldt JD, Baiker A (2003) Appl Phys Lett 82:3360

8. Grunwaldt J-D, Hannemann S, Schroer CG, Baiker A (2006) J Phys Chem B 110:8674

9. Bergwerff JA, van de Water LGA, Visser T, de Peinder P, Leliveld BRG, de Jong KP, Weckhuysen BM (2005) Chem Eur J 11:4592

10. Holzwarth A, Schmidt H-W, Maier WF (1998) Angew Chem Int Ed 37:2644

11. Grunwaldt J-D, Kimmerle B, Hannemann S, Baiker A, Boye P, Schroer CG (2007) J Mater Chem 17:2603

12. Busch OM, Brijoux W, Thomson S, Schuth F (2004) J Catal 222:174

13. Stavitski E, Kox MHF, Swart I, de Groot FMF, Weckhuysen BM (2008) Angew Chem Int Ed 47:3543

14. Hickman DA, Haupfear EA, Schmidt LD (1993) Catal Lett 17:223
15. Tyulenin YP, Savkin VV, Sinev MY, Korchak VN (2002) Kin Catal 43:847

16. Mallens EPJ, Hoebink J, Marin GB (1997) J Catal 167:43

17. Hickman DA, Schmidt LD (1992) J Catal 138:267

18. Vernon PDF, Green MLH, Cheetham AK, Ashcroft AT (1990) Catal Lett 6:181

19. Heitnes K, Lindberg S, Rokstad OA, Holmen A (1995) Catal Today 24:211

20. Yang SW, Kondo JN, Hayashi K, Hirano M, Domen K, Hosono H (2004) Appl Catal A 277:239

21. Rabe S, Nachtegaal M, Vogel F (2007) Phys Chem Chem Phys 9:1461

22. Deutschmann O, Schmidt LD (1998) AIChE J 44:2465

23. Quiceno R, Deutschmann O, Warnatz J, Perez-Ramirez J (2007) Catal Today 119:311

24. Basini L, Aasberg-Petersen K, Guarinoni A, Ostberg M (2001) Catal Today 64:9

25. Grunwaldt J-D, Basini L, Clausen BS (2001) J Catal 200:321

26. Grunwaldt J-D, Kappen P, Basini L, Clausen BS (2002) Catal Lett 78:13

27. Nakagawa K, Ikenaga NO, Kobayashi T, Suzuki T (2001) Catal Today 64:31

28. Basile F, Fornasari G, Trifirò F, Vaccari A (2001) Catal Today 64:21

29. Horn R, Williams KA, Degenstein NJ, Schmidt LD (2007) Chem Eng Sci 62:1298

30. Grunwaldt J-D, Baiker A (2005) Catal Lett 99:5

31. Strobel R, Grunwaldt J-D, Camenzind A, Pratsinis SE, Baiker A (2005) Catal Lett 104:9

32. Hannemann S, Grunwaldt JD, Lienemann P, Gunther D, Krumeich F, Pratsinis SE, Baiker A (2007) Appl Catal A 316:226

33. Grunwaldt J-D, Caravati M, Hannemann S, Baiker A (2004) Phys Chem Chem Phys 6:3037

34. Clausen BS, Grabaek L, Topsoe H, Hansen LB, Stoltze P, Nørskov JK, Nielsen OH (1993) J Catal 141:368

35. Sankar G, Thomas JM, Chen J, Wright PA, Barrett PA, Greaves GN, Catlow CRA (1995) Nucl Instrum Methods Phys Res B 97:37

36. Clausen BS, Topsoe H, Frahm R (1998) Adv Catal 42:315

37. Grunwaldt J-D, Clausen BS (2002) Topics Catal 18:37

38. Hsieh CK, Yeyinmen IM, Hsia JJG, Keskin I (1967) In: Touloukian YS (ed) Thermophysical properties of high temperature solid materials. Macmillan Company, New York, p 405

39. Frahm R (1989) Physica B 158:342

40. Newton MA, Jyoti B, Dent AJ, Fiddy SG, Evans J (2004) Chem Commun 2382

41. Hannemann S, Grunwaldt J-D, van Vegten N, Baiker A (2007) Catal Today 54

42. Bazin D, Rehr JJ (2003) J Phys Chem B 107:12398

43. York APE, Xiao TC, Green MLH (2003) Topics Catal 22:345

44. Gelin P, Primet M (2002) Appl Catal B 39:1

45. Freni S, Calogero G, Cavallaro S (2000) J Power Source 87:28

46. Williams KA, Leclerc CA, Schmidt LD (2005) AIChE J 51:247

47. Rabe S, Truong TB, Vogel F (2005) Appl Catal A 292:177

48. Hu YH, Ruckenstein E (2004) Adv Catal 48:297

49. Li BT, Kado S, Mukainakano Y, Miyazawa T, Miyao T, Naito S, Okumura K, Kunimori K, Tomishige K (2007) J Catal 245:144 